\title{
Mathematical model of a drive system with synchronous motors and vertical pumps
}

\author{
Andrzej Szafraniec ${ }^{1, *}$ \\ ${ }^{1}$ Kazimierz Pulaski University of Technology and Humanities in Radom, Faculty of Transport and \\ Electrical Engineering, ul. Malczewskiego 29, 26-600 Radom, Poland
}

\begin{abstract}
The paper presents a mathematical model of an electrical load node consisting of a power transformer and synchronous motors which rotate vertical pumps using non-rigid transmission. Modified principle of Hamilton-Ostrogradsky served as the basis for construction of the model. Using the developed mathematical model of the node, electromechanical transients in the object are studied. The resultant system of dynamic state nonlinear differential equations is introduced in the normal Cauchy's form. Computer simulation findings are displayed by means of figures; they are under ongoing analysis.
\end{abstract}

\section{Introduction}

Electrotechnical systems for generation, transmission and consumption of energy occupy an important place in the national economy. A wide range of relevant electrical devices are in one way or another involved in energy delivery to a consumer (transformers, power transmission, lines, etc.). Many generally introduce an inductive load, which maximizes voltage of electrical grids. Therefore, the issue of reactive power compensation is significant.

There are many ways of reactive power compensation, starting with the use of compensating batteries and ending with a variety of semiconductor devices. Use of synchronous electric drives, especially of high and medium power, is an important and effective way of reactive energy compensation. In other words, it is advisable to replace asynchronous motors with synchronous driving motors. The present paper proposes to use a similar procedure with an electrical load node including synchronous pump drives [1-3].

\section{Aim of the paper}

To construct a mathematical model of an electrical load node with non-rigid transmission pump synchronous and then analyse unsteady electro-mechanical processes in the abovementioned node.

\footnotetext{
${ }^{*}$ Corresponding author: a.szafraniec@uthrad.pl
} 
To fulfill this objective, a generalized method which involves modifications of the integral variational Hamilton-Ostrogradsky principle was used by introducing an extended non-conservative Lagrange function [1], [4-8].

\section{Mathematical model of the load node}

A mathematical model of the electrical load node (Fig. 1) is traditionally constructed starting with formation of the extended Lagrange function. For this purpose, we introduce generalized coordinates for the Holonomic system, Fig.1, Fig. 2:

for a power transformer:

$q_{(1-6)}=Q_{1 A}, Q_{1 B}, Q_{1 C}, Q_{2 A}, Q_{2 B}, Q_{2 C}-$ charges in windings;

for a synchronous motors:

$q_{(7-12)}, k=Q_{S A, k}, Q_{S B, k}, Q_{S C, k}, Q_{R D, k}, Q_{R Q, k}, Q_{R f, k}$ - charge in phase windings of a motor stator and rotor $(D$ - damper (starting) winding along the $d$ - axis, $Q$ - along the $q$ - axis, $f$ excitation winding);

for a non-rigid transmission of the electric drives:

$q_{(13,14)}, k=\gamma_{1, k}, \gamma_{2, k}$ - rotation angles of the motors rotor and pumps ;

for a vertical pump:

$q_{15, k}=V_{k}$ - liquid volume passing through each of the pumps.

We will also determine the corresponding generalized velocities:

$\dot{q}_{(1-6)}, \dot{q}_{(7-12), k}=i_{(1-6)}, i_{(7-12), k}$ - current;

$\dot{q}_{(13,14), k}=\omega_{1, k}, \omega_{2, k}$ - rotation velocities; $\dot{q}_{15, k}=Q_{k}$ - pumping efficiency.
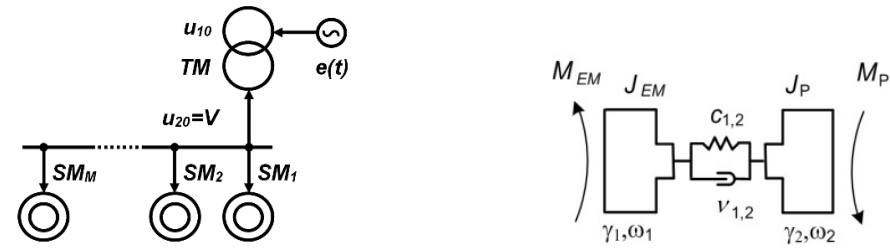

Fig. 1. An electrical diagram of the load node. Fig. 2. Non-rigid transmission of the driving pump.

Extended non-conservative Lagrangian looks as follows:

$$
L^{*}=\tilde{T}^{*}-P^{*}+\Phi^{*}-D^{*}
$$

where: $L^{*}$ - advanced non-conservative Lagrangian function, $\tilde{T}^{*}$ - kinetic co-energy, $P^{*}$ - potential energy, $\Phi^{*}$ - dissipation energy, $D^{*}$ - energy of external potential forces [1], [3-4], [9-10].

Then the elements of the Lagrange function (1) will look as follows:

$$
\begin{gathered}
\tilde{T}^{*} \equiv\left[\tilde{T}_{T M}^{*}\right]+\left[\sum_{k=1}^{M} \tilde{T}_{S M, k}^{*}\right]+\left[\sum_{k=1}^{M} T_{\mathrm{T}, k}^{*}\right]+\left[\sum_{k=1}^{M} T_{P, k}^{*}\right]= \\
=\sum_{j=1}^{3}\left[\int_{0}^{i_{1 j}} \Psi_{10 j} d i_{10 j}+\int_{0}^{i_{2 j}} \Psi_{20 j} d i_{20 j}\right]+\sum_{k=1}^{M}\left\{\sum_{j=1}^{3} \int_{0}^{i_{S j, k}} \Psi_{S j, k} d i_{S j, k}+\right. \\
\left.\left.+\sum_{1}^{m} \int_{0}^{i_{R m, k}} \Psi_{R m, k} d i_{R m, k}\right]+\frac{J_{1, k} \omega_{1, k}^{2}}{2}+\frac{J_{2, k} \omega_{2, k}^{2}}{2}+\frac{L_{\Sigma, k} Q_{k}^{2}}{2}\right\}
\end{gathered}
$$




$$
\begin{gathered}
P^{*}=\sum_{k=1}^{M} \frac{c_{1,2, k}\left(\gamma_{2, k}-\gamma_{1, k}\right)}{2}, j=A, B, C, m=D, Q, f \\
\Phi^{*}=\sum_{j=1}^{3}\left[\int_{0}^{t} r_{1} i_{10 j}^{2} d \tau+\int_{0}^{t} r_{2} i_{20 j}^{2} d \tau\right]+\sum_{k=1}^{M}\left\{\sum_{j=1}^{3} \int_{0}^{t} r_{S j, k} i_{S j, k}^{2} d \tau+\right. \\
\left.+\sum_{m=1}^{3} \int_{0}^{t} r_{R m, k} i_{R m, k}^{2} d \tau+\frac{v_{1,2, k}\left(\omega_{2, k}-\omega_{1, k}\right)}{2}+\frac{1}{2} \int_{0}^{t} R_{\Sigma, k} Q_{k}^{2} d \tau\right\} \\
D^{*}=\int_{0}^{t}\left(u_{0 A} i_{10 A}+u_{0 B} i_{10 B}+u_{0 C} i_{10 C}+u_{f} i_{f}\right) d \tau
\end{gathered}
$$

where the indices denote: $T M$ - power transformer, $S M$ - synchronous motor, $T$ - non-rigid transmission, $P$ - vertical pump, $\Psi$ - flux linkage $r$ - windings resistance of the transformer and the synchronous motor, $u$ - supply voltage of the load node.

After forming the non-conservative Lagrange function on this basis, we insert it into the action functionality according to Hamilton, then obtain a variation of the latter.

$$
S=\int_{t_{1}}^{t_{2}} L^{*} d t, \quad \delta S=\delta \int_{t_{1}}^{t_{2}} L^{*} d t=\int_{t_{1}}^{t_{2}} \delta L^{*} d t=0
$$

and taking into account the dependencies

$$
M_{E M, k}=\frac{\partial\left[\tilde{T}_{E M}^{*}\right]}{\partial \gamma}, \quad \rho g\left(H_{\Gamma}-H_{0}\right)_{k}=\frac{\partial\left[\tilde{T}_{\Sigma}^{*}\right]}{\partial V}
$$

where $M_{E M}$ - electromagnetic moment of the motor, $\rho$ - liquid density, $g$ - gravitational acceleration, $H_{\Gamma}$ - pump lifting height physical lifting height of liquid lifting.

The equality of the functional extremum (6) can be considered a mathematical model of the object, Fig. 1, Fig. 2.

To reduce the volume of mathematical transformations [11] we will express the finite equation of the dynamic state of the electrical load node in matrix-vector form. It is also worth mentioning that the drive synchronous motors of the node are the salient pole, which allows for considering them in a linear version [1].

$$
\begin{gathered}
\frac{d \mathbf{i}_{10}}{d t}=\mathbf{A}_{11,0}\left(\mathbf{u}_{10}-\mathbf{r}_{10} \mathbf{i}_{10}\right)+\mathbf{A}_{12,0}\left(\mathbf{V}-\mathbf{r}_{20} \mathbf{i}_{20}\right) \\
\frac{d \mathbf{i}_{20}}{d t}=\mathbf{A}_{21,0}\left(\mathbf{u}_{10}-\mathbf{r}_{10} \mathbf{i}_{10}\right)+\mathbf{A}_{22,0}\left(\mathbf{V}-\mathbf{r}_{20} \mathbf{i}_{20}\right) \\
\frac{d \boldsymbol{\Psi}_{S, k}}{d t}=\mathbf{V}-\mathbf{r}_{S, k} \mathbf{i}_{S, k}, \quad \frac{d \boldsymbol{\Psi}_{R, k}}{d t}=\mathbf{u}_{R, k}-\mathbf{r}_{R, k} \mathbf{i}_{R, k} \\
\mathbf{V} \equiv \mathbf{u}_{20} \equiv \mathbf{u}_{S, k}=\operatorname{colon}\left(u_{A} ; u_{B}\right), \quad \mathbf{u}_{R, k}=\operatorname{colon}\left(0 ; 0 ; u_{f}\right)
\end{gathered}
$$




$$
\begin{aligned}
& \frac{d \omega_{1}}{d t}=\frac{1}{J_{E M}}\left(M_{E M}-c_{1,2}\left(\gamma_{1}-\gamma_{2}\right)-v_{1,2}\left(\omega_{1}-\omega_{2}\right)\right) \\
& \frac{d \omega_{2}}{d t}=\frac{1}{J_{P}}\left(c_{1,2}\left(\gamma_{1}-\gamma_{2}\right)+v_{1,2}\left(\omega_{1}-\omega_{2}\right)-M_{P}\right) \\
& \frac{d Q_{k}}{d t}=\frac{1}{L_{\Sigma, k}}\left(\rho_{k} g\left(\mathrm{H}_{G, k}-S_{0, k} Q_{k}^{2}\right)-R_{\Sigma, k} Q_{k}\right)
\end{aligned}
$$

We run the equations of stationary connections:

$$
\begin{aligned}
& \boldsymbol{\Psi}_{S}=\boldsymbol{\alpha}_{S}^{-1} \mathbf{i}_{S}+\boldsymbol{\psi}_{S}, \quad \boldsymbol{\alpha}_{S}^{-1}=\operatorname{diag}\left(L_{\sigma S} ; L_{\sigma S}\right), \boldsymbol{\psi}_{S}=\boldsymbol{\Pi}^{-1} \boldsymbol{\psi}_{R} \\
& \boldsymbol{\Psi}_{R}=\boldsymbol{\alpha}_{R}^{-1} \mathbf{i}_{R}+\mathbf{B} \boldsymbol{\psi}_{R}, \quad \boldsymbol{\alpha}_{R}^{-1}=\operatorname{diag}\left(L_{\sigma D} ; L_{\sigma Q} ; L_{\sigma f}\right), \boldsymbol{\psi}_{R} \equiv \boldsymbol{\psi}=\boldsymbol{\Pi} \boldsymbol{\psi}_{S}
\end{aligned}
$$

Following from that

$$
\begin{gathered}
\boldsymbol{\Psi}_{S}=\boldsymbol{\alpha}_{S}^{*} \boldsymbol{\Psi}_{S}+\mathbf{B}^{\mathrm{T}} \boldsymbol{\alpha}_{R}^{*} \boldsymbol{\Pi}^{-1} \boldsymbol{\Psi}_{R}, \boldsymbol{\alpha}_{S}^{*}=\operatorname{diag}\left(\frac{\alpha_{\sigma S}}{\alpha_{d+} \alpha_{\sigma S}+\alpha_{\sigma D}+\alpha_{\sigma f}}\right. \\
\left.\frac{\alpha_{\sigma S}}{\alpha_{q+} \alpha_{\sigma S}+\alpha_{\sigma Q}}\right), \quad \boldsymbol{\alpha}_{R}^{*}=\operatorname{diag}\left(\frac{\alpha_{\sigma D}}{\alpha_{d+} \alpha_{\sigma S}+\alpha_{\sigma D}+\alpha_{\sigma f}}\right.
\end{gathered}
$$

The currents in the motor windings are determined from (14), (15)

$$
\mathbf{i}_{S}=\boldsymbol{\alpha}_{S}\left(\boldsymbol{\Psi}_{S}-\boldsymbol{\Psi}_{S}\right), \quad \mathbf{i}_{R}=\boldsymbol{\alpha}_{R}\left(\boldsymbol{\Psi}_{R}-\mathbf{B} \boldsymbol{\psi}_{R}\right), \alpha_{j}=\frac{1}{L_{j}}
$$

The electromagnetic torque of a synchronous motor is calculated using [1]:

$$
M_{E M, k}=\sqrt{3} p_{0, k}\left(\Psi_{S B, k} i_{S A, k}-\Psi_{S A, k} i_{S B, k}\right)
$$

Analyzing the equations (8) - (10), it can be observed that in the latter there is an unknown function $\mathbf{V}$ - voltage of the load node. To find the unknown function, the first expression in (17) should be differentiated with respect to time, taking into account the first expression in (10) and the expression in (16)

$$
\frac{d \mathbf{i}_{S, k}}{d t}=\boldsymbol{\alpha}_{S, k}\left(\mathbf{V}-\mathbf{r}_{S, k} \mathbf{i}_{S, k}-\frac{d \boldsymbol{\psi}_{S, k}}{d t}\right)
$$

Then we set the first expression in (16) with respect to time, taking into account the expressions in (10) and (14) and inserting them in the equation (19) 


$$
\begin{aligned}
\frac{d \mathbf{i}_{S, k}}{d t} & =\left(\boldsymbol{\alpha}_{S, k}-\boldsymbol{\alpha}_{S, k} \boldsymbol{\alpha}_{S, k}^{*}\right) \mathbf{V}+\boldsymbol{\alpha}_{S, k}\left(\left(\boldsymbol{\alpha}_{S, k}^{*}-\mathbf{1}\right) \mathbf{r}_{S, k} \mathbf{i}_{S, k}-\right. \\
& \left.-\frac{d \boldsymbol{\Pi}_{k}^{-1}}{d t} \mathbf{B}^{\mathrm{T}} \boldsymbol{\alpha}_{R, k}^{*} \boldsymbol{\Psi}_{R, k}-\boldsymbol{\Pi}_{k}^{-1} \mathbf{B}^{\mathrm{T}} \boldsymbol{\alpha}_{R, k}^{*}\left(\mathbf{u}_{R, k}-\mathbf{r}_{R, k} \mathbf{i}_{R, k}\right)\right)
\end{aligned}
$$

For the load node in Fig. 1. we will write Kirchhoff's First Law and differentiate it with respect to time, taking into account the initial conditions [1]

$$
\mathbf{i}_{20}+\sum_{k=1}^{M} \mathbf{i}_{S, k}=0 \Rightarrow \frac{d \mathbf{i}_{20}}{d t}+\sum_{k=1}^{M} \frac{d \mathbf{i}_{S, k}}{d t}=0
$$

Finally, we will consistently solve the following equations (9), (20) and (21) with respect to $\mathbf{V}$, and will obtain

$$
\begin{gathered}
\mathbf{V}=\left[\mathbf{A}_{22,0}+\sum_{k=1}^{M}\left(\boldsymbol{\alpha}_{S, k}-\boldsymbol{\alpha}_{S, k} \boldsymbol{\alpha}_{S, k}^{*}\right)\right]^{-1}\left[\mathbf{A}_{22,0} \mathbf{r}_{20} \mathbf{i}_{20}-\right. \\
-\mathbf{A}_{21,0}\left(\mathbf{u}_{10}-\mathbf{r}_{10} \mathbf{i}_{10}\right)-\sum_{k=1}^{M} \boldsymbol{\alpha}_{S, k}\left(\left(\boldsymbol{\alpha}_{S, k}^{*}-\mathbf{1}\right) \mathbf{r}_{S, k} \mathbf{i}_{S, k}-\right. \\
\left.\left.-\frac{d \mathbf{\Pi}_{k}^{-1}}{d t} \mathbf{B}^{\mathrm{T}} \boldsymbol{\alpha}_{R, k}^{*} \boldsymbol{\Psi}_{R, k}-\mathbf{\Pi}_{k}^{-1} \mathbf{B}^{\mathrm{T}} \boldsymbol{\alpha}_{R, k}^{*}\left(\mathbf{u}_{R, k}-\mathbf{r}_{R, k} \mathbf{i}_{R, k}\right)\right)\right]
\end{gathered}
$$

It should be noted that the use of the pump equations (13) is complicated by the search for coefficients. For this reason, traditionally, a pump model and a pressure pipeline should be constructed based on the pressure characteristics Fig.3 [9-10], [12-14].

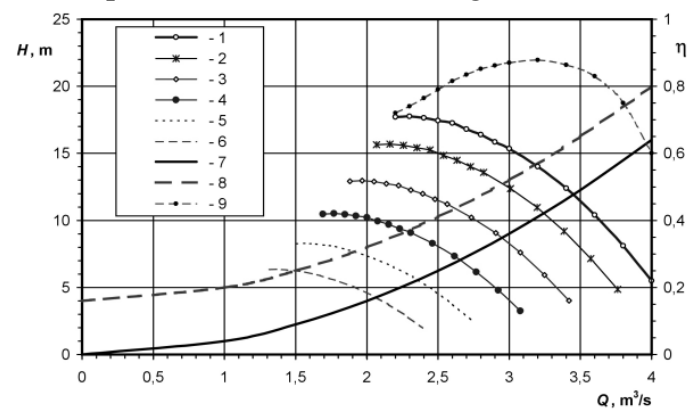

Fig.3. Schedules of the OB 2-87 pump and the pressure pipeline

$\left(D=1200 \mathrm{~mm}, L=1500 \mathrm{~m}, H_{\Gamma}=0\right.$ and $\left.4 \mathrm{~m}\right)$.

Load moments of asynchronous motors for $H_{\Gamma}=0$ and $4 \mathrm{~m}$ are approximated by the exponential function

$$
M_{P 0}\left(\omega_{2}\right)=2,052 \cdot \omega_{2}^{2} ; M_{P 4}\left(\omega_{2}\right)=3,958 \cdot \omega_{2}^{1,856}
$$

The differential equations (8) - (12) are subject to joint integration taking into account the expressions (17), (18), (22), (23). 


\section{Computer simulation findings}

A computer simulation was conducted as follows. A power transformer; $P_{N}=630 \mathrm{~kW}$, $n_{N}=750 \mathrm{rot} / \mathrm{min} ; U_{N}=6 \mathrm{kV} ; u_{f N}=42 \mathrm{~V}, p_{0}=4$ is supplied from an infinite power source. Two synchronous electric drives (the first and the second) applied the load; the drives rotated vertical pumps and a pressure pipeline $\left(D=1200 \mathrm{~mm}, L=1500 \mathrm{~m}, H_{\Gamma}=0\right.$ - the first pump and $4 \mathrm{~m}$ - the second) by means of long shafts, for example, water-intake facilities of thermal power plants. The shaft parameters are as follows: $l_{0}=6 \mathrm{~m}, G=8.1 \cdot 10^{10}$ $\mathrm{Nm}, \rho=7850 \mathrm{~kg} / \mathrm{m}^{3}, d_{0}=28 \mathrm{Sm}$.

Two experiments were conducted. The first was to start the system of two motors excitation $u_{f N}=30 \mathrm{~V}$. A part of the second, the initial excitation was $u_{f}=23 \mathrm{~V}$ with a further increase in voltage according to the linear law up to $u_{f}=48 \mathrm{~V}$ during the time $t \in$ $[35 ; 50] \mathrm{s}$. The load moments of two pumps (the first and the second) are presented in Fig. 3 and expression (23). Also, a reduction gearbox with a gear ratio $i=1.28$ was inserted into the transmission of both electric drives. Since the second electric drive is loaded to the maximum, the simulation findings are presented for it.

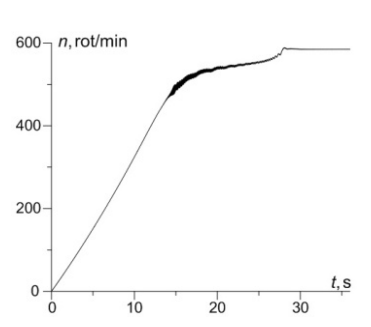

Fig. 4. Rotation speed of the pump.

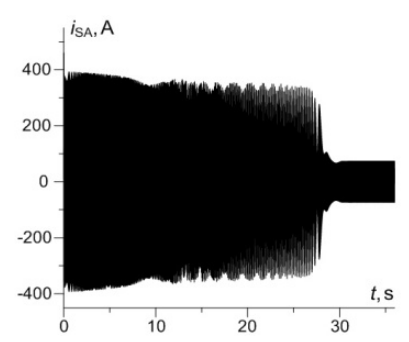

Fig. 5. Current in phase A of the second motor armature winding.

Figures 4 and 5 show rotation speed and current in the stator winding of the motor. A in the stator winding of the second motor. At the time $t=28 \mathrm{~s}$, excitation winding was inserted in excitation voltage $u_{f N}=30 \mathrm{~V}$ from a practically closed state. After entering the device into synchronization, the determined process takes place after $t=30 \mathrm{~s}$, the settled process occurred after $t=30 \mathrm{~s}$; the rotation frequency and current became stable.

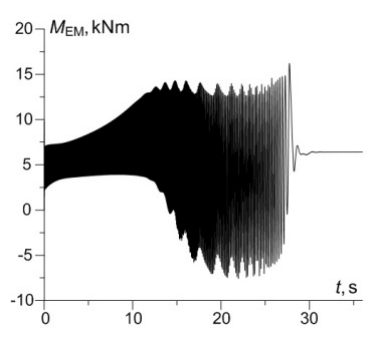

Fig. 6. Electromagnetic moment of the second motor.

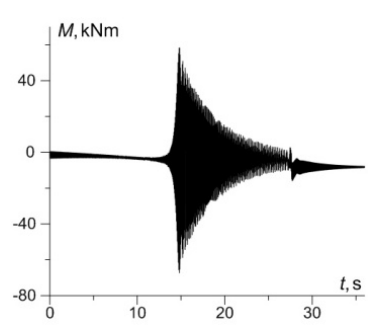

Fig. 7. Elastic moment in the shaft of the second electric drive.

Figures 6, 7 show the electromagnetic moment of the second motor and the elastic moment in the shaft of the second electrical drive. It is important to note the rather high value of the elastic moment up to $70 \mathrm{kNm}$, which is more than ten times higher than the nominal value of the motor. Such a high value of the moment generates fluctuations of the electromagnetic moment functions. 


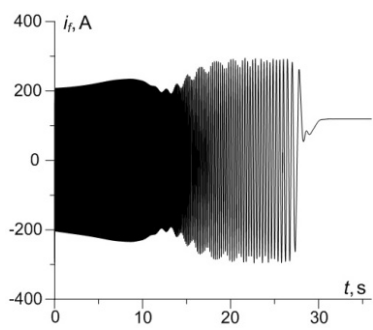

Fig. 8. Current in the rotor excitation winding of the second motor.

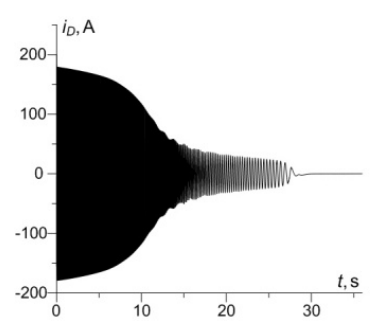

Fig. 9. Rotor winding current along the $D$ axis of the second motor.

Figures 8 and 9 show two types of current in the rotor windings. The first current in the excitation winding of the machine and the second - in the damper (starting) winding along the d-axis. Analyzing the figures, it can be observed that, as the rotation velocity increases, the current frequency in both windings decreases, and after the machine is synchronized, the excitation current takes an established value and damping types of current (along both the axes) become equal to zero.

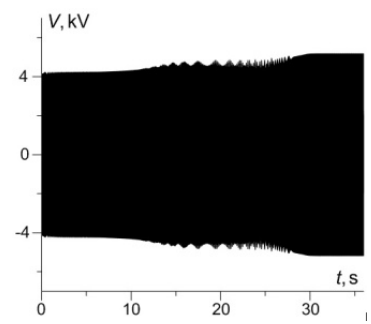

Fig. 10. Voltage in phase A of the load node.

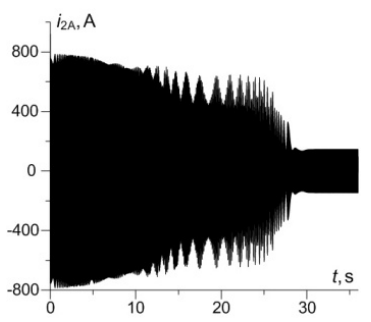

Fig. 11. Current in phase A of the secondary winding of the power transformer.

Figures 10 and 11 show the phase voltage and current in phase A of the secondary winding of the power transformer. It should be noted that the voltage of the secondary winding of the power transformer is the voltage of the electrical load node. The two Figures also show significant fluctuations, the nature of which is connected to the fluctuations in the non-rigid transmission of the electric drives. In other words, an obvious example of the electromechanical energy conversion throughout the load node can be observed here [11], [15-17].

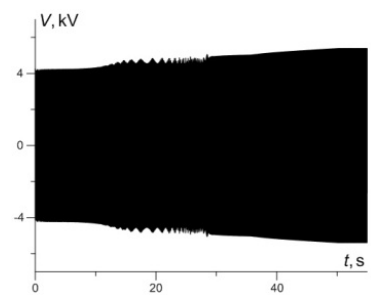

Fig. 12. Voltage in phase A of the secondary transformer winding (2nd experiment).

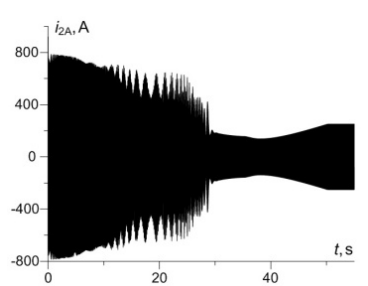

Fig. 13. Current in phase A of the secondary power transformer winding (2nd experiment).

Figures 12 and 13 show the phase voltage of the load unit and current in phase A of the power transformer for the second experiment. Upon reaching the steady state in the system, during $t=35 \mathrm{~s}$, the voltage increases up to $t=50 \mathrm{~s}$ according to the linear law. The first figure shows the voltage amplitude increase from $\mathrm{U}=4700 \mathrm{~V}$ to $\mathrm{U}=5500 \mathrm{~V}$. At the nominal value of the load node $U=4900 \mathrm{~V}$. In other words, the phenomenon of 
overcompensation can be observed, which is also undesirable in electrical load nodes. Figure 13 is an example of this phenomenon. During the steady process, current increases significantly more than 1.5 times (see Fig. 11). Moreover, this current is of a capacitive nature.

\section{Conclusions}

1. Application of interdisciplinary approaches to complex modeling of dynamic systems in various physical sciences greatly extends research capabilities. This is especially relevant to applied problems of electro-mechanics, when the basics of electrical engineering, applied mechanics, hydrodynamics and other fields are often involved in mathematical models of objects.

2. An important point during mathematical modeling of electrical load nodes is formation of a methodology for calculating voltage of such nodes. In fact, the theory of ordinary differential equations, applicable to this procedure, makes a substantial contribution to solving of this problem.

3. Use of synchronous electric drives as elements of electrical load nodes helps to solve the problem of reactive power compensation effectively, on the one hand, and to provide fixed mechanical characteristics of an electric drive, on the other.

4. During asynchronous acceleration of synchronous electric drives with non-rigid transmission the problem of increased elastic moments in drive shafts occurs. In fact, use of mathematical modeling allows to recreate the oscillating nature of these moments and therefore to create preconditions for effective reduction of elastic moments in nonrigid transmission of synchronous electric drives.

\section{References}

1. A. Chaban, Principle Gamiltona-Ostrogradskogo in elektromehanichnih systems, (Soroki, Lviv 2015)

2. A. Szafraniec, Modelowanie matematyczne procesów oscylacyjnych w napędzie elektrohydraulicznym o podatnej transmisji ruchu, Przegląd Elektrotechniczny, 12, 167-171, (2017)

3. A. Czaban, M. Lis, Wykorzystanie sztucznej sieci neuronowej do wyznaczania prądu generatora w układzie napędowym silnik PMSM - generator prądu stałego, Przegląd Elektrotechniczny, 6, 272-274, (2014)

4. R. Ortega, A. Loria, P.J. Nicklasson, H. Sira-Ramirez, Passivity-Beast Control of Euler-Lagrange Systems: Mechanical, Electrical and Electromechanical Applications. (Springer Verlag, London 1998)

5. D. Zhang, W. Shi, B. Chen, X. Guan, Unsteady flow analisys and experimental investigation of axial-flow pump, Journal of Hydrodynamics, 22(1), 35-43, (2010)

6. M. Lis, Modelowanie matematyczne procesów nieustalonych w elektrycznych układach napędowych o złożonej transmisji ruchu, (Wydawnictwo Politechniki Częstochowskiej, Częstochowa 2013)

7. P. Pukach, Investigation of Bending Vibrations in Voigt-Kelvin Bars with Regard for Nonlinear Resistance Forces, Journal of Mathematical Sciences, 215, 71-78, (2016)

8. A. Szafraniec, Mathematical Model of Asynchronous Pump Drive and Power Transformer Drive System with Complex Motion Transmission, Control of Power Systems 13th International Scientific Conference CPS 2018, Tatranské Matliare Tatranská Lomnica, (2018) 
9. Z. Łukasik, A. Czaban, A. Szafraniec, V. Żuk, The mathematical model of the drive system with asynchronous motor and vertical pump, Przegląd Elektrotechniczny, 1 133-138 (2018)

10. Z. Łukasik, A. Czaban, A. Szafraniec, Mathematical model of asynchronous pump drive with distributed mechanical parameters, Przegląd Elektrotechniczny, 6, 155-159, (2018)

11. M. Lis, A. Szafraniec, Model matematyczny synchronicznego układu pompowego o podatnej transmisji ruchu, Maszyny Elektryczne - Zeszyty Problemowe, 118, 165-170, (2018)

12. T. Zawilak, Silnik synchroniczny wzbudzany magnesami trwałymi w napędzie pompy dużej mocy, Maszyny Elektryczne. Zeszyty Problemowe, 106, 247-251, (2015)

13. W. Jędral, K. Karaśkiewicz, J. Szymczyk, Badanie nieustalonych stanów pracy i charakterystyk zupełnych pomp wirowych, Instal, 11, 21-24, (2013)

14. W. Mandrus, W. Żuk, Hydraulika, napędy hydrauliczne i pneumatyczne maszyn wojskowych, (ACB, Lwów 2013)

15. T. Glinka, Dynamika silnika indukcyjnego i synchronicznego po wyłączeniu i ponownym załączeniu napięcia, Maszyny Elektryczne - Zeszyty Problemowe, 1, 1-14, (2017)

16. T. Zawilak, J. Zawilak, Synchronous motors excited by permanent magnets in high power drives, Przegląd Elektrotechniczny, 2, 173-176, (2017)

17. A. Popenda, Mathematical Modelling of Real Transmission Shafts and Mechanical Connections with Clearances, Przegląd Elektrotechniczny 1, 189-192 (2017) 